\title{
Differences in fat-related dietary patterns between black, Hispanic and white women: results from the Women's Health Trial Feasibility Study in Minority Populations
}

\author{
Alan R Kristal ${ }^{*}$, Ann L Shattuck and Ruth E Patterson \\ Cancer Prevention Research Program, Division of Public Health Sciences, \\ Fred Hutchinson Cancer Research Center, PO Box 19024, Seattle, Washington 98109-1024, USA
}

Submitted 1 May 1998: Accepted 10 October 1998

\begin{abstract}
Objective: This report examines how sources of fat and patterns of fat-related dietary habits differed between black, Hispanic and white women participating in a randomized trial of a low-fat diet intervention.

Design: The intervention consisted of group sessions, which met weekly for 6 weeks, biweekly for 6 weeks and monthly for 9 months, and included didactic nutrition education and activities to provide motivation for sustained dietary change. Outcomes included total fat and fat from nine food groups from a food frequency questionnaire (FFQ), and a summary scale and five subscales that measure fat-related dietary habits.

Setting/subjects: Data are from 1702 post-menopausal women, recruited from clinical centres in Atlanta, Birmingham and Miami, with dietary assessments at baseline and 6 months post-randomization.

Results: Total fat intake was similar across race/ethnic groups at baseline, yet there were many differences in sources of fat and fat-related dietary habits. For example, blacks consumed less fat from dairy foods and more fat from meats than whites. Effects of the intervention on total fat intake or the summary fatrelated dietary habits scale did not differ across race/ethnicity groups. There were, however, many differences in how the intervention affected sources of fat and fatrelated dietary habits. For example, the intervention effect for added fats (e.g. butter and salad dressings) was $-8.9 \mathrm{~g}$ for blacks and $-12.0 \mathrm{~g}$ for whites $(P<0.05)$. The intervention effect for adopting low-fat meat purchasing and preparation methods was larger for blacks than whites, and the intervention effect for replacing high-fat foods with fruits and vegetables was larger for Hispanics than whites.

Conclusions: This study demonstrates that, if properly designed, a single nutrition intervention programme can work well even in groups with culturally diverse dietary patterns.
\end{abstract}

\section{Keywords \\ Minority groups Dietary intervention}

One of the Healthy People Year 2000 objectives is to reduce chronic disease risk factors in minority and low-income populations ${ }^{1}$. There has been little research on how to adapt nutrition interventions developed for a general population for use in minority groups with different dietary patterns. In 1992, the National Heart Lung and Blood Institute and the National Cancer Institute funded the Women's Health Trial Feasibility Study in Minority Populations (WHT:FSMP) ${ }^{2}$. The WHT:FSMP was a randomized, clinical trial to examine the feasibility of future studies targetting black, Hispanic and low socioeconomic status (SES) women to test low-fat, high fruit and vegetable diets for prevention of cardiovascular disease and cancer. One specific aim of the WHT:FSMP was to test whether a single nutrition intervention programme would be effective among women with markedly different culturally associated dietary patterns.

A primary finding from the WHT:FSMP was that the intervention effects for percentage of energy from fat were similar among black and white women, but significantly smaller among Hispanics. The purpose of this paper is to better understand how the behavioural effects of the intervention differed across black, white and Hispanic participants. Specifically, it examines how sources of fat and patterns of fat-related dietary habits differed between racial and ethnic groups at baseline, and how dietary patterns in each racial and ethnic group changed as a result of the intervention. Results can be used to better understand how to design interventions for culturally diverse populations. 


\section{Methods}

Reports on the WHT:FSMP study design and baseline findings ${ }^{2}$ and primary dietary ${ }^{3}$ and serological endpoints ${ }^{4}$ have been described elsewhere. In brief, three clinical centres (Emory University in Atlanta, the University of Alabama at Birmingham, and the University of Miami in Florida), a coordinating centre (Fred Hutchinson Cancer Research Center in Seattle) and two institutes of the National Institutes of Health (National Cancer Institute and the National Heart, Lung and Blood Institute) collaborated in this trial. Each clinical centre had minority participant recruitment goals: $50 \%$ or more black women in Atlanta; $50 \%$ or more Hispanic women in Miami; and proportional representation of the local population including 29\% blacks and 18\% women of low SES in Birmingham. In this report, we describe women who self-identified as 'white or Caucasian, not Hispanic' as whites, 'black, not Hispanic' as blacks, and 'Hispanic, black' or 'Hispanic, white' as Hispanics. Participants were aged 50-79 years, post-menopausal and consumed at least $36 \%$ of energy from fat as estimated from a FFQ administered during screening. Exclusions included a history of major chronic diseases, mental illness, extreme obesity and an inability or unwillingness to maintain a 4-day diet record. Randomization was $60 \%$ to the dietary intervention group and $40 \%$ to the control group.

The nutrition intervention goals of the WHT:FSMP were to reduce fat intake to $20 \%$ or less of total energy, to increase servings of fruits and vegetables, and to reduce saturated fat intake. The intervention was based on the programme developed in the Women's Health Trial Feasibility Study ${ }^{5}$, with extensive modifications that included: (i) revising written materials and exercises to be at a sixth grade reading level; (ii) expanding the range of foods and preparation methods, in particular to include those of US southern blacks and Cubans; and (iii) translating all materials, exercises and assessment instruments into Cuban Spanish. The nutrition intervention was delivered in group sessions led by centrally trained registered dietitians, which met weekly for 6 weeks, biweekly for 6 weeks, monthly for 9 months, and then quarterly. Sessions integrated both nutritional and behavioural topics, and consisted of problem-solving, role playing, sharing experiences, food tasting and didactic nutrition education. Each participant received a personal goal for fat intake based on height and estimated energy intake from the FFQ at baseline, which she monitored using a self-administered and scored 'fat scan'. Participants selected the specific changes in food choices and food preparation methods that best fitted their own eating pattern, preferences and lifestyle. In Miami, participants could join intervention groups run in Spanish or
English. Details of the principles and content of this intervention have been published ${ }^{6}$.

\section{Dietary assessment}

This report uses data from two dietary assessment instruments completed at baseline and 6 months postrandomization. A self-administered, optically scanned FFQ was used to assess changes in both total fat intake and sources of fat by food group. A fat-related dietary habits questionnaire (DHQ) was used to assess changes in food purchasing, preparation and selection. These dietary assessment instruments were available in both Spanish and English, and are described below.

\section{Food frequency questionnaire}

The WHT:FSMP FFQ was based on instruments used previously in the Women's Health Trial Vanguard ${ }^{6}$ and Full Scale ${ }^{7}$ studies and the Working Well Trial ${ }^{8}$, to which we added fat-modified and regionally and culturally specific foods. The WHT:FSMP FFQ consisted of 100 food items or food groups, with 19 introductory questions (e.g. 'When you ate chicken, how often did you eat the skin?') and four summary questions (e.g. 'How often did you eat fruit, not counting juices?') used to refine nutrient calculations. The time reference for all questions was 'in the last 3 months'. The nutrient database from the University of Minnesota Nutrition Coordinating Center ${ }^{9}$ and algorithms for FFQ analysis ${ }^{10}$ are described in detail elsewhere. We modified the software to calculate grams of fat from nine food groups, which are described in Appendix 1. Details on the validity and reliability of the WHT:FSMP FFQ are reported elsewhere ${ }^{11}$.

\section{Fat-related dietary habits questionnaire}

The DHQ was based on an instrument originally developed to assess food purchasing and preparation patterns related to adopting a low-fat diet ${ }^{12}$. This instrument has been modified to measure fat-related dietary habits in clinical intervention studies ${ }^{13}$, randomized trials of self-help nutrition interventions ${ }^{14}$ and in telephone-based dietary surveys ${ }^{15}$. The DHQ used in the WHT:FSMP included 23 items, which were combined into five subscales: 'avoid fat as flavouring', 'avoid frying', 'modify meats', 'substitute lower-fat products' and 'replace with fruits and vegetables'. The summary score was calculated as the mean of the five subscale scores. Responses to the items were scored on a four-point scale ('usually or always' 'often' 'sometimes' and 'rarely or never') and were coded 1 through 4 to correlate positively with fat intake. Appendix 2 shows the five subscales, their individual items and the internal consistency and validity of the scales at baseline and 6 months post-randomization. The internal consistency of the subscales ranged from 0.46 to 0.72 at baseline and from 0.49 to 0.77 at 6 months, 
and for the summary scale from 0.55 at baseline to 0.60 at 6 months, which are similar to previous results using this instrument ${ }^{16}$. Validity of the fat-related dietary habits scores, defined as the correlation coefficient between the DHQ summary scale score and percentage of energy from fat from the mean of FFQ and 4-day food record results, was 0.46 at baseline and at 6 months was 0.60 among intervention participants and 0.58 among controls.

\section{Statistical methods}

Due to the study design, in which almost all the Hispanics were recruited from the Miami clinic only, data from all the study centres cannot be combined and still allow separation of effects of clinic from those of race and ethnicity. Therefore, this report gives contrasts of black vs. white for participants in Atlanta and Birmingham combined and of Hispanic vs. white for participants in Miami only. The sample used for analyses in this report is a subset of those randomized into the WHT:FSMP. Participants who could not be classified as black, Hispanic or white $(n=11)$ and those who did not have dietary measures at both baseline and 6 months post-intervention were excluded. Analyses based on the DHQ included $88.7 \%$ of blacks and $92.6 \%$ of whites in Birmingham and Atlanta, and $43.5 \%$ of Hispanics and $64.6 \%$ of whites in Miami. In addition, analyses based on the FFQ excluded participants who did not reasonably complete this questionnaire, defined as total energy intake under 600 or greater than $5000 \mathrm{kcal}$. Analyses based on the FFQ included
$70.7 \%$ of blacks and $81.0 \%$ of whites in Birmingham and Atlanta, and $35.5 \%$ of Hispanics and $56.0 \%$ of whites in Miami.

Tests for differences in age, education or income across race/ethnic groups (black vs. white and Hispanic vs. white) used Student's $t$-test and chisquare tests. Tests for differences at baseline in fat intake (from the FFQ) and in fat-related dietary habits (from the DHQ) across race/ethnic groups used Student's $t$-test. To compare the effects of the intervention across race/ethnic groups, we defined the intervention effect for a food group or diet habit scale $X$ as:

$$
\left(\bar{X}_{b}-\bar{X}_{f}\right)_{I}-\left(\bar{X}_{b}-\bar{X}_{f}\right)_{C}
$$

where the subscripts $b$ and $f$ refer to baseline and follow-up, and the subscripts $I$ and $C$ refer to the intervention and control groups. In practice, intervention effects were calculated using multiple regression models. These models predicted change from baseline to 6 months, and used the baseline value as a covariate and a coefficient indicating intervention or control group membership as the measure of the intervention effect. Tests for differences in intervention effects between race or ethnic groups were based on adding an indicator variable to these regression models for race or ethnicity and its interaction with treatment group. Among intervention women only, results are given showing change from baseline to 6 months for each of the individual items from the DHQ. Tests for

Table 1 Demographic and dietary characteristics of WHT:FSMP participants at baseline, by race/ethnicity and clinic given as percentages

\begin{tabular}{|c|c|c|c|c|c|}
\hline & \multicolumn{2}{|c|}{ Atlanta and Birmingham } & \multicolumn{2}{|c|}{ Miami } & \multirow[b]{2}{*}{$\begin{array}{c}\text { Total sample } \\
(n=1702)\end{array}$} \\
\hline & $\begin{array}{c}\text { Black } \\
(n=530)\end{array}$ & $\begin{array}{c}\text { White } \\
(n=820)\end{array}$ & $\begin{array}{l}\text { Hispanic } \\
(n=151)\end{array}$ & $\begin{array}{c}\text { White } \\
(n=201)\end{array}$ & \\
\hline $\begin{array}{l}\text { Age (years) } \\
\quad \text { Mean } \pm \text { SD } \\
50-59 \\
60-69 \\
70+\end{array}$ & $\begin{array}{l}59.6 \pm 6.7 \\
60.0 \\
31.1 \\
8.9\end{array}$ & $\begin{array}{c}60.2 \pm 6.6 \\
53.4 \\
37.8 \\
8.8\end{array}$ & $\begin{array}{c}60.2 \pm 6.1 \\
56.3^{*} \\
37.1 \\
6.6\end{array}$ & $\begin{array}{c}61.5 \pm 6.6 \\
46.8 \\
40.8 \\
12.4\end{array}$ & $\begin{array}{c}60.2 \pm 6.6 \\
54.9 \\
36.0 \\
9.0\end{array}$ \\
\hline $\begin{array}{l}\text { Education (years) } \\
\quad<12 \\
12 \\
13-15 \\
16+ \\
\text { Unknown }\end{array}$ & $\begin{array}{l}14.2^{*} \\
14.9 \\
33.2 \\
36.2 \\
1.5\end{array}$ & $\begin{array}{r}11.7 \\
18.4 \\
38.2 \\
30.1 \\
0.7\end{array}$ & $\begin{array}{l}11.9^{* * *} \\
29.1 \\
33.8 \\
24.5 \\
0.7\end{array}$ & $\begin{array}{r}4.5 \\
20.4 \\
31.3 \\
43.8 \\
0.0\end{array}$ & $\begin{array}{r}11.6 \\
18.5 \\
35.4 \\
33.5 \\
0.9\end{array}$ \\
\hline $\begin{array}{l}\text { Household income } \\
\quad<15000 \\
15000-49999 \\
\geqslant 50000 \\
\text { Unknown }\end{array}$ & $\begin{array}{l}23.4^{\star * \star} \\
52.6 \\
16.0 \\
7.9\end{array}$ & $\begin{array}{r}7.1 \\
50.2 \\
30.1 \\
12.6\end{array}$ & $\begin{array}{l}20.5^{\star \star \star} \\
56.3 \\
10.6 \\
12.6\end{array}$ & $\begin{array}{r}7.0 \\
41.8 \\
36.3 \\
14.9\end{array}$ & $\begin{array}{l}13.3 \\
50.5 \\
24.7 \\
11.4\end{array}$ \\
\hline $\begin{array}{l}\text { Nutrient intake† } \\
\text { Energy (kcal) } \\
\text { Fat }(\mathrm{g}) \\
\text { Fat (\% energy) }\end{array}$ & $\begin{array}{c}(n=422) \\
1763 \pm 795 \\
78.7 \pm 40.2 \\
39.8 \pm 6.7\end{array}$ & $\begin{array}{c}(n=718) \\
1833 \pm 656 \\
82.3 \pm 35.6 \\
39.8 \pm 6.7\end{array}$ & $\begin{array}{c}(n=123) \\
2000 \pm 827 \\
87.1 \pm 43.1 \\
38.4 \pm 6.9\end{array}$ & $\begin{array}{c}(n=174) \\
1826 \pm 605 \\
82.3 \pm 35.0 \\
39.9 \pm 7.4\end{array}$ & $\begin{array}{c}(n=1437) \\
1825 \pm 712 \\
81.6 \pm 37.6 \\
39.7 \pm 6.8\end{array}$ \\
\hline
\end{tabular}

${ }^{*} \chi^{2}, P<0.05$, vs. white; ${ }^{* * *} \chi^{2}, P<0.001$, vs. white.

†From food frequency questionnaire; means \pm SD. 

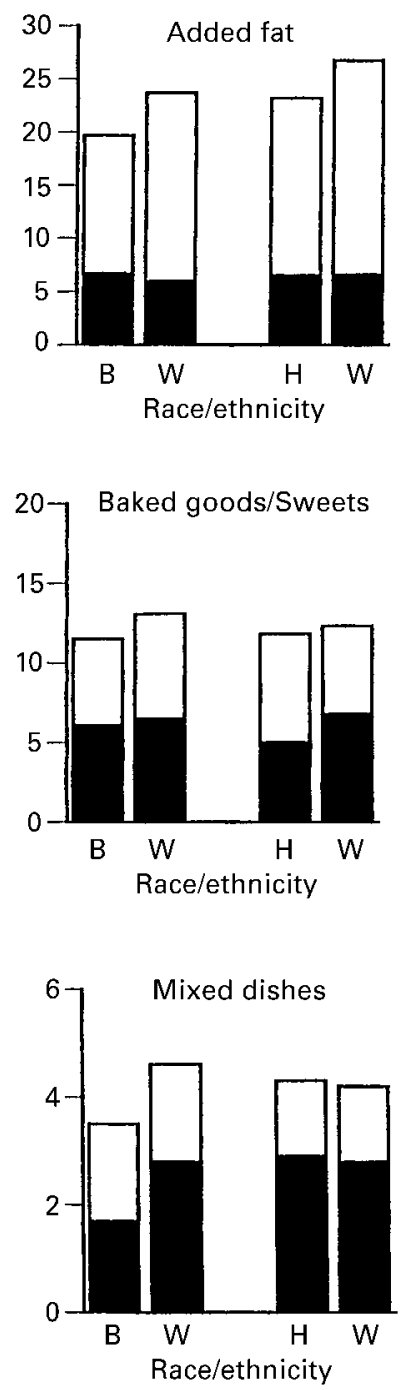
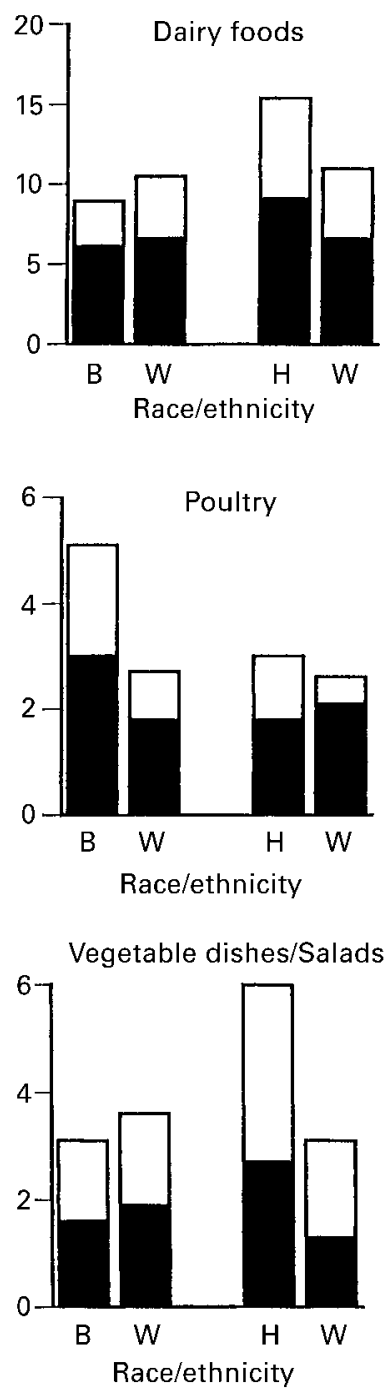
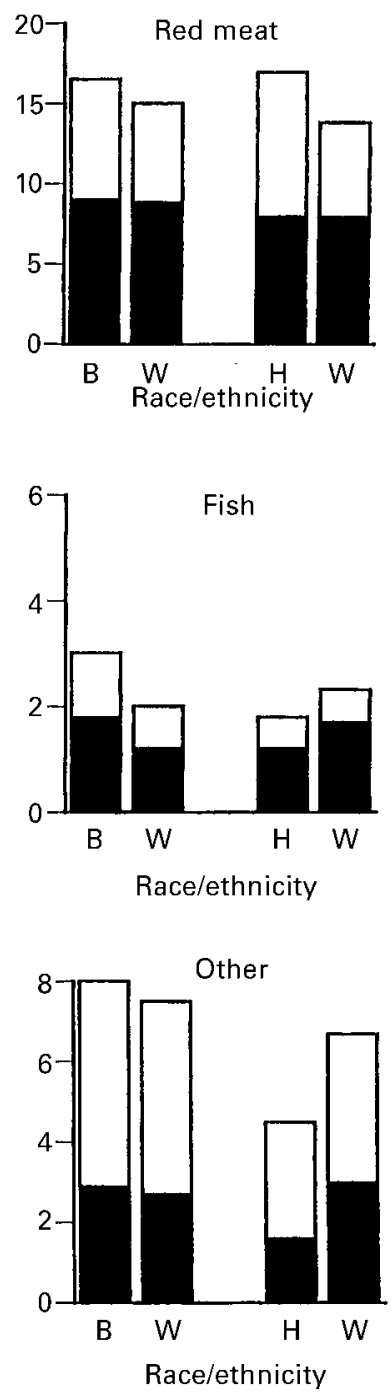

Baseline

6 Months

Fig. 1 Differences in sources of dietary fat intake (in grams) by WHT:FSMP intervention participants at baseline and 6 months, by race/ ethnicity $(\mathrm{B}=$ black: $\mathrm{W}=$ white: $\mathrm{H}=$ hispanic)

changes in each DHQ item used paired $t$-tests, and tests of whether changes differed by race/ethnic group used Student's $t$-test.

\section{Results}

Table 1 gives demographic characteristics and baseline dietary intake, comparing black with white participants in the Birmingham and Atlanta clinics, and Hispanic with white participants in the Miami clinic. In Atlanta and Birmingham, more blacks had graduated from college or had not completed high school than whites, and had lower incomes. In Miami, Hispanics were slightly younger, had less education and had lower incomes than whites. There were no differences in baseline nutrient intake across race/ethnic groups.
Figure 1 shows differences across race/ethnic groups in fat intake from nine food groups, among intervention women only. At baseline, the largest source of fat in all race/ethnic groups was from added fats; these were a larger source of fat intake for whites than for blacks or Hispanics. Other notable differences at baseline include higher fat intakes from dairy foods among Hispanics, from poultry among blacks, and from vegetables/salads among Hispanics. The largest decreases in all race/ethnic groups between baseline and 6 months were fat from added fats, red meat and baked goods. At 6 months, there were only modest differences across race/ethnic groups in sources of fat, suggesting that the intervention was effective in lowering fat from all food groups.

Table 2 gives statistical analyses of the associations of 
Table 2 Mean fat intake $(\mathrm{g})$ at baseline and effects of the WHT:FSMP dietary intervention at 6 months, by food group, race/ethnicity and clinic

\begin{tabular}{|c|c|c|c|c|}
\hline \multirow[b]{2}{*}{ Food group ${ }^{1}$} & \multicolumn{2}{|c|}{ Atlanta and Birmingham } & \multicolumn{2}{|c|}{ Miami } \\
\hline & $\begin{array}{c}\text { Black } \\
(n=422)\end{array}$ & $\begin{array}{l}\text { White } \\
(n=718)\end{array}$ & $\begin{array}{l}\text { Hispanic } \\
(n=123)\end{array}$ & $\begin{array}{c}\text { White } \\
(n=174)\end{array}$ \\
\hline \multicolumn{5}{|l|}{ Added fat } \\
\hline $\begin{array}{l}\text { Baseline } \\
\text { Intervention effect }{ }^{2}\end{array}$ & $\begin{array}{l}19.4^{\star *} \\
-8.9^{*}\end{array}$ & $\begin{array}{r}23.0 \\
-12.0\end{array}$ & $\begin{array}{l}23.1 \\
-8.1\end{array}$ & $\begin{array}{l}25.4 \\
-9.5\end{array}$ \\
\hline \multicolumn{5}{|l|}{ Dairy foods } \\
\hline Baseline & $8.6^{* *}$ & 10.3 & $14.9^{* *}$ & 11.1 \\
\hline Intervention effect & $-1.3^{\star}$ & -2.9 & -1.5 & -3.6 \\
\hline \multicolumn{5}{|l|}{ Red meat } \\
\hline Baseline & $16.3^{*}$ & 14.7 & $17.2^{*}$ & 13.7 \\
\hline Intervention effect & -5.0 & -4.2 & -6.6 & -5.5 \\
\hline \multicolumn{5}{|l|}{ Baked goods } \\
\hline Baseline & $10.9^{\star *}$ & 12.9 & 10.7 & 11.6 \\
\hline Intervention effect & $-2.8^{*}$ & -4.4 & -2.1 & -2.0 \\
\hline \multicolumn{5}{|l|}{ Poultry } \\
\hline Baseline & $5.2^{\star *}$ & 2.7 & 3.0 & 2.7 \\
\hline Intervention effect & $-2.5^{\star \star}$ & -0.5 & -0.6 & -0.7 \\
\hline \multicolumn{5}{|l|}{ Fish } \\
\hline Baseline & $3.2^{* \star}$ & 1.9 & $1.7^{* *}$ & 2.5 \\
\hline Intervention effect & $-1.0^{* *}$ & -0.4 & -0.4 & -0.2 \\
\hline \multicolumn{5}{|l|}{ Mixed dishes } \\
\hline Baseline & $3.2^{* \star}$ & 4.5 & 4.5 & 4.2 \\
\hline Intervention effect & -1.4 & -0.9 & -1.0 & -1.1 \\
\hline \multicolumn{5}{|l|}{ Vegetables/salads } \\
\hline Baseline & $3.1^{*}$ & 3.6 & $6.4^{* *}$ & 3.1 \\
\hline Intervention effect & -1.2 & -1.2 & -2.2 & -0.9 \\
\hline \multicolumn{5}{|l|}{ Other } \\
\hline Baseline & 7.5 & 7.2 & $4.0^{\star *}$ & 6.5 \\
\hline Intervention effect & -3.3 & -3.1 & -1.7 & -2.5 \\
\hline \multicolumn{5}{|l|}{ Total fat } \\
\hline Baseline & 78.7 & 82.3 & 87.1 & 82.3 \\
\hline Intervention effect & -27.4 & -29.4 & -24.6 & -26.0 \\
\hline \multicolumn{5}{|c|}{ Per cent energy from fat } \\
\hline Baseline & 39.8 & 39.8 & 38.4 & 39.9 \\
\hline Intervention effect & -11.3 & -12.1 & $-5.9^{*}$ & -11.0 \\
\hline
\end{tabular}

race/ethnicity with fat intake at baseline. Fat intake is given as total grams and grams from each of nine food groups. There were no differences across race/ethnic groups in total fat intake at baseline, however there were many significant differences between race/ethnic groups in sources of fat. Compared with whites, blacks consumed less fat from added fat, dairy foods, baked goods, mixed dishes and vegetables/salads, and more fat from red meat, poultry and fish; Hispanics consumed more fat from dairy foods, red meat and vegetables/salads, and less from fish and 'other foods' (eggs, snack chips, nuts and cereals).

Table 2 also gives the association of race/ethnicity with intervention effects, defined as the mean change in the intervention group minus the change in controls. There were no differences across race/ethnic groups in overall intervention effects on total grams of fat. The main study result, shown at the bottom of Table 2, was a significantly smaller intervention effect for percentage of energy from fat among Hispanics. In all race/ethnic groups, intervention effects were largest for added fat and red meat. Compared with whites, intervention effects were significantly larger among blacks for poultry and fish, and smaller for added fat, dairy foods and baked goods. Due to the small sample size, no differences in intervention effects were significant between Hispanics and whites, though there was a suggestion that the intervention effect for Hispanics was smaller for dairy foods and larger for vegetables/ salads.

Table 3 gives the mean scores for the fat-related dietary habits scales at baseline, as well as the intervention effects at 6 months. Higher scores on the DHQ scales correspond to higher fat intakes and, based 
Table 3 Baseline mean dietary habits scale scores ${ }^{1}$ and effects of the WHT:FSMP dietary intervention at 6 months, by race/ethnicity and clinic

\begin{tabular}{|c|c|c|c|c|}
\hline & \multicolumn{2}{|c|}{ Atlanta and Birmingham } & \multicolumn{2}{|c|}{ Miami } \\
\hline & $\begin{array}{c}\text { Black } \\
(n=530)\end{array}$ & $\begin{array}{c}\text { White } \\
(n=820)\end{array}$ & $\begin{array}{l}\text { Hispanic } \\
(n=151)\end{array}$ & $\begin{array}{c}\text { White } \\
(n=201)\end{array}$ \\
\hline $\begin{array}{l}\text { Avoid fat as flavouring } \\
\text { Baseline } \\
\text { Intervention effect }^{2}\end{array}$ & $\begin{array}{c}3.10^{\star *} \\
-0.42^{*}\end{array}$ & $\begin{array}{r}3.25 \\
-0.58\end{array}$ & $\begin{array}{l}2.76^{\star *} \\
-0.31\end{array}$ & $\begin{array}{r}3.13 \\
-0.54\end{array}$ \\
\hline $\begin{array}{l}\text { Avoid frying } \\
\text { Baseline } \\
\text { Intervention effect }\end{array}$ & $\begin{array}{l}2.10^{\text {** }} \\
-0.36\end{array}$ & $\begin{array}{r}1.83 \\
-0.32\end{array}$ & $\begin{array}{l}1.86^{* * *} \\
-0.31\end{array}$ & $\begin{array}{r}1.64 \\
-0.25\end{array}$ \\
\hline $\begin{array}{l}\text { Modify meat } \\
\text { Baseline } \\
\text { Intervention effect }\end{array}$ & $\begin{array}{l}2.30^{\star *} \\
-0.50\end{array}$ & $\begin{array}{r}1.94 \\
-0.39\end{array}$ & $\begin{array}{l}2.08^{\star} \\
-0.30\end{array}$ & $\begin{array}{r}2.20 \\
-0.43\end{array}$ \\
\hline $\begin{array}{l}\text { Substitute } \\
\text { Baseline } \\
\text { Intervention effect }\end{array}$ & $\begin{array}{l}2.93^{\star \star *} \\
-0.80\end{array}$ & $\begin{array}{r}2.79 \\
-0.85\end{array}$ & $\begin{array}{r}2.95 \\
-0.61\end{array}$ & $\begin{array}{r}2.84 \\
-0.70\end{array}$ \\
\hline $\begin{array}{l}\text { Replace with fruits/ve } \\
\text { Baseline } \\
\text { Intervention effect }\end{array}$ & $\begin{array}{l}2.75^{\star *} \\
-0.35\end{array}$ & $\begin{array}{r}2.94 \\
-0.26\end{array}$ & $\begin{array}{r}2.92 \\
-0.43\end{array}$ & $\begin{array}{r}2.88 \\
-0.30\end{array}$ \\
\hline $\begin{array}{l}\text { Summary score } \\
\text { Baseline } \\
\text { Intervention effect }\end{array}$ & $\begin{array}{l}2.64^{\star *} \\
-0.48\end{array}$ & $\begin{array}{r}2.55 \\
-0.48\end{array}$ & $\begin{array}{r}2.50 \\
-0.39\end{array}$ & $\begin{array}{r}2.54 \\
-0.43\end{array}$ \\
\hline
\end{tabular}

on earlier studies ${ }^{17}$, a 1 unit decrease in the summary DHQ score corresponds to a 13 percentage point decrease in per cent of energy from fat. There were many differences at baseline in fat-related dietary habits across race/ethnic groups. Compared with whites, blacks had significantly higher scores on the summary score and on the subscale scores for avoid frying, modify meat and substitute, and lower scores for avoid fat as flavouring and replace with fruits/vegetables. Hispanics had significantly higher scores than whites for the avoid frying and substitute subscales, and lower scores for avoid fat as a flavouring and modify meat. Intervention effects for the summary score did not differ by race/ethnicity, and were largest in all race/ ethnic groups for the substitute subscale. We interpret differences in intervention effects between race/ethnic groups of 0.10 as meaningful (though they are not necessarily statistically significant; this difference corresponds to 1.3 percentage points in per cent of energy from fat). Using this criterion, the intervention effect was smaller for blacks compared with whites for avoid fat as flavouring, and was larger for blacks for modify meats and replace with fruits/vegetables. The intervention effect for Hispanics compared with whites was larger for replace with fruits/vegetables, and smaller for avoid fat as a flavouring and modify meat.

Table 4 gives the mean changes among intervention women in individual items from the DHQ. The numbers of women answering each item varies, because respondents skip over any item that asks about a food they do not eat. For example, if a women does not eat chicken, she will not respond to questions on how often she removes the skin or eats chicken fried. The largest change made by all race/ethnic groups, though based only on the $26 \%$ who baked at home, was to use less fat in baking. Other dietary habits with at least a mean 1.0 decreased score in all race/ ethnic groups included using low-fat or non-fat mayonnaise, low-fat cheese, non-stick cooking spray and low-calorie salad dressing. Compared with whites, blacks made smaller changes in using low-fat cheese, adding fat to vegetables, potatoes and breads, using meatless spaghetti sauce and eating salads without dressing, and larger changes in eating fried fish, taking skin off chicken and trimming fat off meat. Compared with whites, Hispanics made smaller changes in adding fat to potatoes and breads, taking skin off chicken and using meatless spaghetti sauce.

\section{Discussion}

There were many differences in the ways that black, Hispanic and white participants adopted a low-fat diet. Below we discuss how dietary patterns and intervention effects differed across race/ethnic groups, the limitations to these analyses and the implications of the results to the design of future dietary interventions.

There were two substantial differences in sources of fat and in dietary patterns between blacks and whites. At baseline, blacks consumed more fat from meat, 
Table 4 Mean changes from baseline to 6 months in individual items ${ }^{1}$ from the fat-related dietary habits questionnaire, intervention group only, by race/ethnicity and clinic ${ }^{2}$

\begin{tabular}{|c|c|c|c|c|}
\hline & \multicolumn{2}{|c|}{ Atlanta and Birmingham } & \multicolumn{2}{|c|}{ Miami } \\
\hline & $\begin{array}{c}\text { Black } \\
(n=256-326)^{3}\end{array}$ & $\begin{array}{c}\text { White } \\
(n=431-494)^{3}\end{array}$ & $\begin{array}{c}\text { Hispanic } \\
(n=81-100)^{3}\end{array}$ & $\begin{array}{c}\text { White } \\
(n=108-133)^{3}\end{array}$ \\
\hline Use less fat in baked items ${ }^{4}$ & -1.3 & -1.5 & -1.8 & -1.5 \\
\hline Eat low-fat cheese & $-1.1^{\star *}$ & -1.4 & -1.1 & -1.2 \\
\hline Use low-fat/non-fat mayonnaise & -1.2 & -1.2 & -1.0 & -1.2 \\
\hline Use non-stick spray to sauté foods ${ }^{4}$ & -1.0 & -1.2 & -1.1 & -1.1 \\
\hline Eat vegetables with added fat ${ }^{5}$ & -1.1 & -1.2 & -0.9 & -1.0 \\
\hline Eat potatoes without added fat & $-0.8^{* * *}$ & -1.3 & $-0.7^{*}$ & -1.1 \\
\hline Eat non-fat frozen desserts & $-0.8^{\star \star \star}$ & -1.2 & -0.9 & -1.0 \\
\hline Use low-calorie (diet) salad dressing & -1.0 & -1.0 & -1.0 & -1.0 \\
\hline Trim fat from meat before cooking & -0.9 & -0.9 & -0.8 & -1.1 \\
\hline Eat bread/rolls without butter or margarine & $-0.5^{\star \star \star}$ & -1.0 & $-0.5^{\star \star}$ & -1.1 \\
\hline Eat fried fish ${ }^{5}$ & $-0.9^{*}$ & -0.7 & -0.7 & -0.7 \\
\hline Use low-fat or non-fat milk & -0.9 & -0.7 & -0.5 & -0.6 \\
\hline Take skin off chicken & $-1.0^{\star * *}$ & -0.5 & $-0.4^{*}$ & -0.8 \\
\hline Trim visible fat from red meat & $-0.8^{\star * *}$ & -0.5 & -0.4 & -0.6 \\
\hline Eat fried chicken ${ }^{5}$ & -0.6 & -0.5 & -0.6 & -0.5 \\
\hline Eat fruit for dessert & -0.6 & -0.5 & -0.6 & -0.6 \\
\hline Eat fried potatoes ${ }^{5}$ & -0.5 & -0.5 & -0.5 & -0.5 \\
\hline Eat extra-lean ground beef & -0.4 & -0.5 & -0.3 & -0.7 \\
\hline Use meatless spaghetti sauce & $-0.2^{* *}$ & -0.5 & $-0.2^{\star}$ & -0.6 \\
\hline Eat fruit for snacks & -0.4 & -0.4 & -0.6 & -0.3 \\
\hline Eat vegetables for snacks & -0.3 & -0.4 & -0.4 & -0.4 \\
\hline Eat fried vegetables ${ }^{5}$ & -0.3 & -0.3 & -0.4 & -0.3 \\
\hline Eat salads with no dressing & $-0.1^{*}$ & -0.3 & -0.2 & -0.2 \\
\hline
\end{tabular}

${ }^{*} P<0.05$, vs. white; ${ }^{* *} P<0.01$, vs. white; ${ }^{* * *} P<0.001$, vs. white.

1 On a 4-point scale responses were $1=$ usually or always; $2=$ often; $3=$ sometimes; $4=$ rarely or never.

${ }^{2}$ All changes in dietary habits were statistically significant $(P<0.05)$ except those shown in bold.

${ }^{3}$ Range of number of responses (excluding items with superscript of 4). Numbers vary because participants skip items for foods they do not eat.

${ }^{4}$ Sample size considerably smaller for these items.

${ }^{5}$ Item score reversed before analysis.

poultry and fish, and they used high-fat preparation methods such as frying, not removing skin from chicken and not trimming excess fat. Whites ate more fat added to foods as flavouring, such as fats added to vegetables or on breads. Consistent with these baseline differences, intervention effects were larger for whites for avoiding fat as a flavouring and for blacks for modifying meat to be lower in fat. There were three notable differences in dietary patterns between Hispanics and whites at baseline. Hispanics added less fat to foods as a flavouring, but ate more fat from fried vegetables and high-fat salads. Hispanics also consumed more fat from meat, though they were more likely to use low-fat techniques for its preparation. Again, differences in intervention effects were consistent with differences at baseline, as effects in each race/ethnic group tended to be larger for those foods and dietary habits that accounted for more fat at baseline. There was an additional important difference between Hispanics and others in the way they made dietary changes. Though reductions in total fat were similar across race/ethnic groups, Hispanics replaced a smaller proportion of energy from fat with energy from other macronutrients. Thus, the reduction in percentage of total energy from fat in Hispanics was smaller than for blacks or whites. Overall, these results suggest that the intervention was successful in helping participants with diverse dietary patterns identify and change those dietary patterns that provided significant amounts of fat. The intervention was not successful among Hispanics, however, in promoting increased intake of energy from non-fat sources to compensate for reduced fat intake.

There are few studies that have directly compared food use patterns across race/ethnic groups that can be used for comparison. In a detailed analysis of the National Health Interview Survey comparing US blacks, Hispanics and whites, several differences in fat-related food consumption were found ${ }^{18}$. Compared with other women, blacks ate more fried poultry and fish, and Hispanics ate less breakfast and lunch meats. White women consumed more milk, though they were more likely to use low-fat varieties. Use of fats as spreads was highest among whites, intermediate among blacks, and lowest among Hispanics. Patterson and colleagues ${ }^{19}$ analysed data from a large sample of women screened to participate in the Women's Health Initiative. Compared with white women, blacks and Hispanics practised fewer low-fat food preparation methods, such as trimming meats or not frying, and used fewer specially manufactured reduced-fat products. There is some consistency with the findings reported here, in particular higher use of added fats by white women and higher use of fried foods by black women. We know of 
no intervention studies that have examined how changes in dietary patterns differed across race/ethnic groups.

We believe that there are several reasons why the WHT:FSMP dietary intervention was successful in all race/ethnic groups. One important reason was that the intervention programme was broadly inclusive of culturally diverse dietary and lifestyle patterns. With the exception of groups conducted in Spanish, all intervention groups included women of different ethnic, racial and socioeconomic backgrounds. Another key reason was that the intervention was designed to accommodate individual dietary patterns and food preferences. The intervention gave principles on how to lower fat in food purchasing and preparation, and focused on enhancing motivation to reach and maintain a personalized 'fat gram goal'. This is in contrast to interventions that prescribe specific foods or menus. Results of this study are consistent with a perspective that considers both planned menus and prohibited foods inappropriate for achieving long-term dietary change.

The most important limitation to this study is that results may not be generalizable to representative samples of black, Hispanic and white women. Participants in the WHT:FSMP had high fat intakes at baseline, were interested in nutrition and health, and were highly motivated to participate in nutrition research. In addition, most Hispanic participants were Cuban-Americans, and dietary patterns differ among Hispanic subgroups ${ }^{20}$. Another limitation is that the sample for the analyses reported here was a select group of WHT:FSMP participants who had completed both baseline and 6-month dietary assessments. The generalizability of Hispanic vs. white comparisons is particularly weak, because only $36 \%$ of Hispanics had completed two valid FFQs. This was due, in part, to the disruption to Miami clinic operations caused by Hurricane Andrew in August 1992. Strengths of this report include the use of two validated instruments to measure dietary patterns ${ }^{11,12}$, and the large numbers of minority participants available for analysis.

We conclude that a single dietary intervention programme can work well in culturally diverse groups. The intervention approach used in the WHT:FSMP was to educate participants about how to choose a low-fat diet and motivate them to do so, without prescribing specific foods or meal patterns. This approach may be effective for promoting longterm dietary change because it gives participants skills to select a personalized low-fat dietary plan. When working with minority populations, nutritionists should carefully evaluate whether the intervention materials are sufficiently flexible to accommodate a broad range of foods and food preparation patterns.

\section{References}

1 Healthy People 2000: National Health Promotion and Disease Prevention Objectives. DHHS (PHS) Publication No. 91-50213. Washington, DC: US Department of Health and Human Services, 1991.

2 Bowen D, Clifford CK, Coates R, et al. The Women's Health Trial Feasibility Study in Minority Populations: design and baseline descriptions. Ann. Epidemiol. 1996; 6: 507-19.

3 Coates RJ, Bowen DJ, Kristal AR, et al. The Women's Health Trial Feasibility Study in Minority Populations: changes in dietary intakes. Am. J. Epidemiol. (in press).

4 Oberman A, Feng Z, Lewis CE, et al. Response of plasma lipids to a low-fat diet in post-menopausal women: the Women's Health Trial Feasibility Study in Minority Populations (submitted for publication).

5 Henderson MM, Kushi LH, Thompson DJ, et al. Feasibility of a randomized trial of a low-fat diet for the prevention of breast cancer: dietary compliance in the Women's Health Trial Vanguard Study. Prev. Med. 1990; 19: 115-33.

6 Tinker LF, Burrows ER, Henry H, Patterson RE, Rupp JW, Van Horn L. The Women's Health Initiative: overview of the nutrition components. In: Kris-Etherton P, Krummel D, eds. Nutrition in Women's Health. Frederick, Maryland: Aspen Publishers, 1995: 510-42.

7 White E, Shattuck AL, Kristal AR, et al. Maintenance of a lowfat diet: follow-up of the Women's Health Trial. Cancer Epidemiol. Biomarkers Prev. 1992; 1: 315-23.

8 Heimendinger J, Feng Z, Emmons K, et al. The Working Well Trial: baseline dietary and smoking behaviors of employees and related worksite characteristics. The Working Well Research Group. Prev. Med. 1995; 24: 180-93.

9 Schakel SF, Sievert YA, Buzzard IM. Sources of data for developing and maintaining a nutrient database. J. Am. Diet. Assoc. 1988; 88: 1268-71.

10 Kristal AK, Shattuck AL, Williams AE. Food frequency questionnaires for diet intervention research. In: Proceedings of the 17th National Nutrient Databank Conference, June 1992. Washington, DC: International Life Sciences Institute, 1994: 110-25.

11 Kristal AR, Feng Z, Coates RJ, Oberman A, George V. Associations of race, ethnicity, education, and dietary intervention with the validity and reliability of a food frequency questionnaire. The Women's Health Trial Feasibility Study in Minority Populations. Am. J. Epidemiol. 1997; 146: 856-69.

12 Kristal AR, Shattuck AL, Henry HJ. Patterns of dietary behavior associated with selecting diets low in fat: reliability and validity of a behavioral approach to dietary assessment. J. Am. Diet. Assoc. 1990; 90: 214-20.

13 Kristal AR, White E, Shattuck AL, et al. Long-term maintenance of a low-fat diet: durability of fat-related dietary habits in the Women's Health Trial. J. Am. Diet. Assoc. 1992; 92: 553-9.

14 Beresford SAA, Curry SJ, Kristal AR, Lazovich D, Feng Z, Wagner EH. A low-intensity dietary intervention in primary care practice: the eating patterns study. Am.J. Public Health 1997; 87: 610-16.

15 Patterson RE, Kristal AR, Shannon J, Hunt JR, White E. Validity of a brief household pantry inventory as an environmental indicator of individual dietary intake. Am. J. Public Health 1997; 87: 272-5.

16 Shannon J, Kristal AR, Curry SJ, Beresford SAA. Application of a behavioral approach to measuring dietary change: the fat- and fiber-related diet behavior questionnaire. Cancer Epidemiol. Biomarkers Prev. 1997; 6: 355-62.

17 Kristal AR, Beresford SAA, Lazovich D. Assessing change in diet intervention research. Proceedings of the First International Conference on Dietary Assessment Methods, St 
Paul (MN), 20-23 Sept. 1992. Am. J. Clin. Nutr. 1994; 59 (Suppl.): S185-9.

18 Patterson BH, Harlan LC, Block G, Kahle L. Food choices of whites, blacks, and Hispanics: data from the 1987 National Health Interview Survey. Nutr. Cancer 1995; 23: 105-19.

19 Patterson RE, Kristal AR, Coates R, et al. Low-fat diet practices of older women: prevalence and implications for dietary assessment. J. Am. Diet. Assoc. 1996; 96: 670-9.

20 Loria CM, Bush TL, Carroll MD, et al. Macronutrient intakes among adult Hispanics: a comparison of Mexican Americans, Cuban Americans and mainland Puerto Ricans. Am. J. Public Health 1995; 85: 684-9.

\section{Appendix 1: definitions of food groups, using food items from the WHT:FSMP food frequency questionnaire}

Added fat

Salad dressings

Butter, margarine, sour cream or other fats added to vegetables, potatoes, rice, noodles

Butter, margarine on bread

Mayonnaise and mayonnaise-type spreads on sandwiches and in salads

Gravy

Fats used in cooking

\section{Dairy foods}

Milk, cream, coffee cream

Cheeses, cottage cheese

Yoghurt, frozen yoghurt

Ice cream, ice milk, other frozen desserts

Pudding, custard

\section{Red meat}

Beef, pork, lamb

Ground beef

Stew, pot pie, casserole

Chili

Liver and other organ meats
Pasta with meat sauce

Ham, turkey, bologna, salami, other lunch meats

Hot dogs, sausage

Bacon, breakfast sausage

\section{Baked goods and sweets}

Biscuits, muffins, bread, rolls, crackers, corn bread, tortillas

Pancakes, waffles

Doughnuts, cakes, pies, pastries, cookies

Chocolate, candy bars

\section{Poultry}

Chicken, turkey

\section{Fish}

Fish, shellfish

Tuna, tuna salad, tuna casserole

\section{Mixed dishes}

Macaroni and cheese, lasagna

Pasta with sauce, other than meat sauce

Pizza

Creamy and meat soups

Bean and other soups

\section{Vegetables and salads}

Avocado or guacamole

Coleslaw, potato and pasta salads

Fried vegetables, including summer squash, okra, plantains, sweet potatoes, yams

French fries, fried potatoes, fried rice

Other

Eggs

Snack chips, popcorn

Peanut butter, nuts, seeds

Cereals, dry and cooked 
Appendix 2: internal consistency, reliability and validity of the fat-related dietary habits questionnaire at baseline and 6 months post-intervention

\begin{tabular}{|c|c|c|c|c|c|c|}
\hline \multirow[b]{3}{*}{ Subscale* } & \multicolumn{3}{|c|}{ Cronbach's alpha } & \multicolumn{3}{|c|}{ Correlation with \% energy from fatł } \\
\hline & \multirow[b]{2}{*}{ Baseline } & \multicolumn{2}{|c|}{ Six months } & \multirow[b]{2}{*}{ Baseline } & \multicolumn{2}{|c|}{ Six months } \\
\hline & & Intervention & Control & & Intervention & Control \\
\hline $\begin{array}{l}\text { Avoid fat as flavouring ( } 5 \text { items) } \\
\text { Use meatless tomato sauce on spaghetti/noodles } \\
\text { Eat bread/rolls without butter or margarine } \\
\text { Eat vegetables with butter, margarine or salt pork } \\
\text { Eat potatoes without butter, margarine or sour cream } \\
\text { Eat salads with no dressing }\end{array}$ & 0.46 & 0.49 & 0.54 & 0.31 & 0.49 & 0.41 \\
\hline $\begin{array}{l}\text { Avoid frying (4 items) } \\
\text { Eat fried fisht } \\
\text { Eat fried chickent } \\
\text { Eat ffied vegetables } \uparrow \\
\text { Eat fried potatoes, e.g. French fries/hash browns } \dagger\end{array}$ & 0.62 & 0.58 & 0.58 & 0.32 & 0.39 & 0.32 \\
\hline $\begin{array}{l}\text { Modify meats ( } 4 \text { items) } \\
\text { Take skin off chicken } \\
\text { Trim visible fat from red meat } \\
\text { Eat extra lean ground meat } \\
\text { Trim fat from meat before cooking }\end{array}$ & 0.68 & 0.61 & 0.68 & 0.28 & 0.23 & 0.28 \\
\hline $\begin{array}{l}\text { Substitute lower-fat products ( } 7 \text { items) } \\
\text { Drink } 1 \% \text { or skim milk } \\
\text { Eat low-fat cheese } \\
\text { Eat non-fat ice cream, frozen yogurt or sherbet } \\
\text { Use low-calorie (diet) salad dressings } \\
\text { Use non-stick spray to sauté or fry foods } \\
\text { Use low-fatnon-fat mayonnaise } \\
\text { Use less fat in baked items }\end{array}$ & 0.72 & 0.77 & 0.72 & 0.33 & 0.49 & 0.50 \\
\hline $\begin{array}{l}\text { Replace with fruits and vegetables ( } 3 \text { items) } \\
\text { Eat fruit for dessert } \\
\text { Eat fruit for snacks } \\
\text { Eat vegetables for snacks }\end{array}$ & 0.61 & 0.67 & 0.67 & 0.15 & 0.19 & 0.33 \\
\hline Summary score (mean of subscales) & 0.55 & 0.60 & 0.57 & 0.46 & 0.60 & 0.58 \\
\hline
\end{tabular}

${ }^{*}$ Questionnaire with exact format and wording available from authors.

† Score reversed before analysis.

$\ddagger$ Mean of percent energy from fat from food frequency questionnaire and 4-day food record. 